\title{
Intracytoplasmic Retention of Type VII Collagen and Dominant Dystrophic Epidermolysis Bullosa: Reversal of Defect Following Cessation of or Marked Improvement in Disease Activity
}

\author{
Jo-David Fine, ${ }^{*} \S$ Lorraine B. Johnson, ${ }^{*}+\S$ Donna Cronce, ${ }^{*}$ J. Timothy Wright, + Irene M. Leigh, \\ Martha McCollough,** and Robert A. Briggaman* \\ *Department of Dermatology, School of Medicine; $\uparrow$ Department of Curriculum in Public Health Nursing, School of Public Health; \\ $\ddagger$ Department of Pediatric Dentistry, School of Dentistry, University of North Carolina; §The National Epidermolysis Bullosa \\ Registry, Southern Clinical Center, Chapel Hill, North Carolina, U.S.A.; ףDermatology Department, The London Hospital, and Skin \\ Tumour Laboratory, Imperial Cancer Research Fund, London, U.K.; and **Department of Dermatology, Brooke Army Medical \\ Center, San Antonio, Texas, U.S.A.
}

It has been recently shown that the presence of perinuclear "stellate bodies" within the epidermis in patients with a form of dominant dystrophic epidermolysis bullosa named "transient bullous dermolysis of the newborn" corresponds to collections of type VII collagen. To determine the temporal relationship of this unique immunohistochemical defect with course of clinical disease activity, we have longitudinally studied the expression of two epitopes of type VII collagen (LH 7:2; L3d) in nine patients in four such kindreds by immunofluorescence and immunoelectron microscopic technique. In every infant so studied at the time of active blistering, type VII collagen was detectable primarily within basilar and, to a lesser extent, suprabasilar keratinocytes. In contrast, type VII collagen was detectable solely in linear array along the dermoepidermal junction in skin from each patient following complete cessation or at least marked diminution of visible clinical disease activity. These findings support the hypothesis that the temporary mechanical fragility and blistering of the skin in infants with this rare subset of dominant dystrophic epidermolysis bullosa reflect the presence of reduced amounts of type VII collagen along the dermoepidermal junction, and that this diminution may be the result of either a delay in transport and integration of type VII collagen from basilar keratinocytes into the skin basement membrane or excessive phagocytosis of type VII collagen. Key words: epidermolysis bullosa/genodermatoses/bullous disease/basement membrane/extracellular matrix/type VII collagen/monoclonal antibodies/transient bullous dermolysis of the newborn. J Invest Dermatol 101:232-236, 1993
I n 1985 Hashimoto et al coined the name "transient bullous dermolysis of the newborn" [1] to describe the clinical features in a single infant who developed a sub-lamina densa blistering disease at birth, associated with evidence of dermal collagenolysis and damaged anchoring fibrils, findings quite suggestive of those routinely observed in dominant and recessive forms of dystrophic epidermolysis bullosa (EB). An added finding, however, was the presence of perinuclear stellate-shaped densities within basilar keratinocytes. Intriguingly, clinical evidence of disease activity disappeared within the first year of life. In 1989, Hashimoto and colleagues reported two additional patients with identical clinical and ultrastructural features [2]. In a study of four additional patients with identical findings we recently demonstrated that the perinuclear deposits noted within the lower epidermis in these patients correspond to intracytoplasmic deposits of type VII collagen, suggesting the likelihood that such keratinocytes have

Manuscript received January 15, 1992; accepted for publication April 12, 1993.

Presented in part at the national meeting of the American Federation for Clinical Research, Seattle, Washington, May 1991.

Reprint requests to: Dr. Jo-David Fine, Department of Dermatology, University of North Carolina at Chapel Hill, Room 137, North Carolina Memorial Hospital, CB \#7600, Chapel Hill, NC 27514. a functional defect in the transport of type VII collagen to the extracellular space [3]. Whereas it is clear that blisters did cease to develop in each of these patients and in similarly affected members of their families, little is known about the distribution and intensity of type VII collagen in the skin of these patients following apparent clinical remission. We now report our findings on nine such patients from four different kindreds, and demonstrate that the presence of intracytoplasmic retention of type VII collagen is indeed a self-limited phenomenon, reverting to normal linear distribution along the dermoepidermal junction following cessation of or at least marked reduction in the intensity and frequency of blistering.

\section{MATERIALS AND METHODS}

Sources of Tissues Examined Twelve 4-mm punch biopsies (of freshly induced blisters from the upper inner arm) were obtained for immunofluorescence mapping, monoclonal antibody, and indirect immunoelectron microscopic (IIEM) studies on each of the patients included in the present study. Biopsies on two other previously reported patients (representing two additionally affected kindreds) were re-examined solely by indirect immunofluorescence with another anti-type VII collagen monoclonal antibody (L3d). Each kindred was identified by the presence of intracytoplasmic epidermal deposits of type VII collagen in an affected family member who was biopsied during early infancy. Whenever possible, biopsies were obtained in each proband during and following cessation of blistering (Table I). In one kindred (subjects 4-1 through 4-4), followup biopsy on the proband was 
Table I. Summary of Histochemical Findings Observed in Each Subject in the Study ${ }^{a}$

\begin{tabular}{|c|c|c|c|c|c|c|c|}
\hline \multirow[b]{2}{*}{ Family } & \multirow[b]{2}{*}{ Patient } & \multicolumn{3}{|c|}{ Initial Skin Biopsy (Proband) } & \multicolumn{3}{|c|}{$\begin{array}{l}\text { Followup Skin Biopsy for Proband; } \\
\text { Initial Biopsy for Affected Family Members }\end{array}$} \\
\hline & & $\begin{array}{c}\text { Age at } \\
\text { Time of } \\
\text { Initial Biopsy }\end{array}$ & $\begin{array}{l}\text { IF Findings } \\
\text { (type VII } \\
\text { collagen) }\end{array}$ & $\begin{array}{l}\text { Predominant } \\
\text { IIEM Findings } \\
\text { (type VII collagen } \\
\text { localization) }\end{array}$ & $\begin{array}{c}\text { Current Age; } \\
\text { Age when Last } \\
\text { Blister } \\
\text { Was Noted }\end{array}$ & $\begin{array}{c}\text { IF Findings } \\
\text { (type VII } \\
\text { Collagen) } \\
\text { [LH 7:2; L 3d] }\end{array}$ & $\begin{array}{l}\text { IIEM Findings } \\
\text { type VII } \\
\text { collagen } \\
\text { localization) }\end{array}$ \\
\hline 1 & $1-1$ & 3 months & $\begin{array}{l}\text { Granular intra- } \\
\text { cytoplasmic } \\
\text { deposits }\end{array}$ & $\begin{array}{l}\text { Cytoplasmic } \\
\quad \text { (keratinocyte) }\end{array}$ & $\begin{array}{l}3.5 \text { years; } \\
6 \text { months }\end{array}$ & $\begin{array}{r}\text { Linear DEJ } \\
{[4+; 4+]}\end{array}$ & $\begin{array}{l}\text { Within or } \\
\text { beneath LD }\end{array}$ \\
\hline \multirow[t]{2}{*}{2} & $2-1$ & $5 \mathrm{~d}$ & $\begin{array}{l}\text { Granular intra- } \\
\text { cytoplasmic } \\
\text { deposits }\end{array}$ & $\begin{array}{l}\text { Cytoplasmic } \\
\text { (keratinocyte) }\end{array}$ & $\begin{array}{l}18 \text { months; } \\
3 \text { months }\end{array}$ & $\begin{array}{r}\text { Linear DEJ } \\
{[4+; 4+]}\end{array}$ & $\begin{array}{l}\text { Within or } \\
\text { beneath LD }\end{array}$ \\
\hline & $2-2$ & - & - & - & $\begin{array}{l}36.7 \text { years; } \\
3 \text { months }\end{array}$ & $\begin{array}{r}\text { Linear DEJ } \\
{[4+; 4+]}\end{array}$ & $\begin{array}{l}\text { Within or } \\
\text { beneath LD }\end{array}$ \\
\hline \multirow[t]{2}{*}{3} & $3-1$ & $10 \mathrm{~d}$ & $\begin{array}{l}\text { Granular intra- } \\
\text { cytoplasmic } \\
\text { deposits }\end{array}$ & ND & \multicolumn{3}{|c|}{$\begin{array}{l}\text { Only rare blisters after age } 6 \text { months; followup biopsy } \\
\text { not obtained }\end{array}$} \\
\hline & $3-2$ & - & - & - & $\begin{array}{l}19 \text { years; } \\
6 \text { months }\end{array}$ & $\begin{array}{r}\text { Linear DEJ } \\
{[4+; 4+]}\end{array}$ & ND \\
\hline \multirow[t]{4}{*}{4} & $4-1$ & $6 \mathrm{~d}$ & $\begin{array}{l}\text { Granular intra- } \\
\text { cytoplasmic } \\
\text { deposits }\end{array}$ & ND & $\begin{array}{l}13 \text { months; } \\
\mathrm{N} / \mathrm{A}^{b}\end{array}$ & $\begin{array}{r}\text { Linear DEJ } \\
{[4+; 4+]}\end{array}$ & $\begin{array}{l}\text { Within or } \\
\text { beneath LD }\end{array}$ \\
\hline & $4-2$ & - & - & - & $23 \mathrm{yr} ; \mathrm{N} / \mathrm{A}^{b}$ & $\begin{array}{r}\text { Linear DEJ } \\
{[4+; 4+]}\end{array}$ & $\begin{array}{l}\text { Within or } \\
\text { beneath LD }\end{array}$ \\
\hline & $4-3$ & - & - & - & $11 \mathrm{yr} ; \mathrm{N} / \mathrm{A}^{b}$ & $\begin{array}{r}\text { Linear DEJ } \\
{[4+; 4+]}\end{array}$ & $\begin{array}{l}\text { Within or } \\
\text { beneath LD }\end{array}$ \\
\hline & $4-4$ & - & - & - & $37 \mathrm{yr} ; \mathrm{N} / \mathrm{A}^{b}$ & $\begin{array}{r}\text { Linear DEJ } \\
{[4+; 4+]}\end{array}$ & $\begin{array}{l}\text { Within or } \\
\text { beneath LD }\end{array}$ \\
\hline
\end{tabular}

- LD, lamina densa; ND, not done; N/A, not applicable.

${ }^{b}$ See text for details.

obtained 13 months after onset of disease, at which time blisters were still developing, although at much reduced frequency and intensity. Biopsies were also obtained from every family member with a history of blister formation during infancy. Ultrastructural findings of intracytoplasmic type VII collagen on two of these probands (patients $1-1$ and 2-1), as well as clinical features on each proband and affected relatives, were presented in our original report on this entity [3].

Clinical Summaries of Families 3 and 4 Two affected members were identified in family 3. By exam and/or by history, disease activity was confined to the skin and mouth. The proband, female, developed generalized blisters at birth; during the first few weeks of life, blisters, and erosions also occurred within the oral cavity. Only occasional blisters have occurred since age 6 months, although she has continued to develop milia, primarily over the dorsal aspects of the hands and feet. Early in life some nails were shed, but have since regrown normally. The mother, aged 19 , had a similar generalized blistering process, primarily on the lower extremities, which also ceased to occur by about age 6 months. When seen at $2 \frac{1}{2}$ months of age, the proband was of normal body size and weight. Scattered blisters were noted on the anterior lower legs, anterior trunk, and dorsal aspects of the hands and feet. Scarring was absent. Several fingernails were dystrophic and milia were noted on the hands, feet, elbows, and knees. The oral cavity was normal. In contrast, the mother had a normal skin exam with the exception of a single dystrophic fingernail and a few small atrophic scars over the dorsum of one hand; no evident residual skin fragility was elicitable. Initial biopsy was obtained on the proband at age $10 \mathrm{~d}$; followup biopsy, following clinical remission, was unobtainable.

Four affected members were identified in family 4 . Extracutaneous symptoms were absent in each. The proband, male, had generalized blisters at birth; the oral cavity was also involved with erosions. With age, the frequency and extent of blistering markedly diminished although several blisters and erosions were still visible when the child was first seen by two of us (JDF, LBJ) at age 13 months. Findings at that time included scattered milia, atrophic scarring, and dystrophic toenails; the oral cavity was normal. The father denied ever having had blisters but gave a history and clinical evidence of numerous milia and focal areas of atrophic scars in areas of minor trauma, particularly the dorsal hands. Both great toenails were markedly dystrophic. The proband's 11-year-old aunt gave a history of recurrent blisters that began at age 9 months, and subsequently became less frequent. On exam, the aunt had an erosion on one elbow, a few milia on the dorsal aspects of her hands and fingers, and mild scarring of the elbows, knees, lower legs, and feet. The proband's grandmother had a history of occasional blisters that first began at about age 13. At the time of our evaluation, she had few focal atrophic scars on the elbows, knees, lower legs, and ankles; interspersed were occasional small $(<2 \mathrm{~mm})$ hypopigmented papules but no blisters. Several toenails were absent.

Sources of Immunoreagents Two anti-type VII collagen IgG class monoclonal antibodies were employed. LH 7:2 monoclonal antibody was created by one of us (IML); details of its characterization have been previously reported [4-6]. L3d monoclonal antibody was produced in the laboratory of another of us $(\mathrm{RAB})[7-9]$. Both react against the non-collagenous region of the type VII collagen molecule; details as to the mapping of the epitope site(s) recognized by each antibody are as yet unavailable. Each was used in the form of antibody-rich tissue culture supernatant. Secondary immunoreagents were obtained from Cappel Laboratories (West Chester, $\mathrm{PA})$.

\section{Studies Performed}

Immunofluorescence (Antigenic) Mapping: Immunofluorescence mapping was performed on cryosections of an unfixed skin specimen from each patient, as previously reported $[10,11]$.

Anti-type VII Collagen Monoclonal Antibody Studies: Indirect immunofluorescence studies were performed on 12 cryopreserved specimens from nine subjects, utilizing both anti-type VII collagen monoclonal antibodies. LH $7: 2$ was used over a range of dilutions previously noted to result in the normal expression of the antigen in skin from all normal individuals and those with simplex, junctional, and dominant dystrophic forms of EB, and absent staining in skin from patients with severe generalized variants of recessive dystrophic $\mathrm{EB}[4,6,12]$. L3d was used at $1: 10$ dilution. A two-step staining protocol was employed, as previously reported [12]; each specimen was examined by epi-illumination with a Leitz immunofluorescence microscope.

IIEM Localization of Type VII Collagen: IIEM was performed on tissue sections prepared from a cryopreserved skin specimen from each of seven subjects representing three probands previously documented during early infancy to have primarily basilar keratinocyte-distributed intracytoplasmic deposits of type VII collagen, and four relatives with a positive history of blistering during infancy. Twelve- to fourteen-micrometer-thick unfixed cryosections were prepared; all incubations were performed at room temperature. Tissue sections were incubated with either LH 7:2 monoclonal anti- 

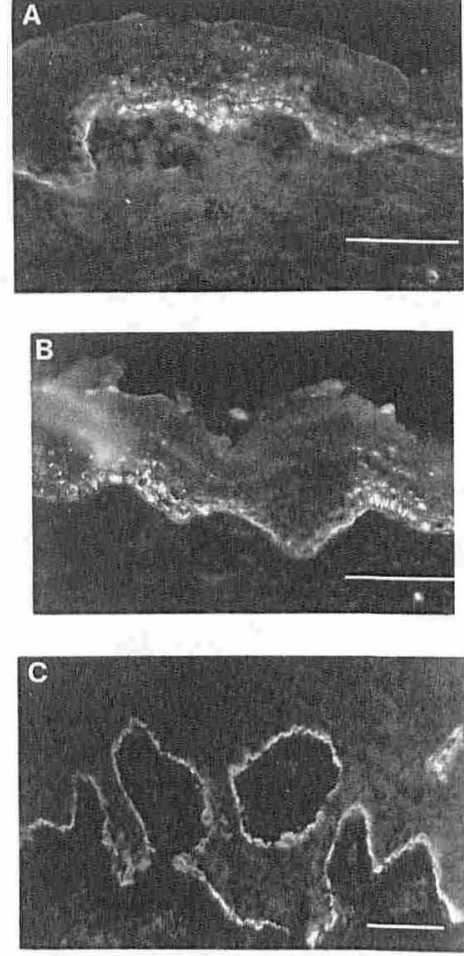

Figure 1. $A, B)$ Indirect immunofluorescence studies of two affected infants with the entity described in this article. At the time of active blistering of the skin, LH 7:2 (A) and L3d (B) anti-type VII collagen monoclonal antibodies demonstrate primarily granular cytoplasmic staining within the epidermis. In contrast, only very weak and patchy staining is detectable along the dermoepidermal junction. Bar, $75 \mu$. C) Following clinical resolution of all blister activity, anti-type VII collagen staining in such cases reverts to a linear homogeneous array along the dermoepidermal junction. Bar, $75 \mu$.

body (1:5-1:40 dilutions; $2 \mathrm{~h}$ ) or L3d monoclonal antibody $(1: 5-1: 40$ dilutions; $2 \mathrm{~h}$ ), and then serially with affinity-purified goat anti-mouse IgG (1:20 dilution; $30 \mathrm{~min})$, rabbit anti-goat $\operatorname{IgG}(1: 2$ dilution; $20 \mathrm{~min})$, goat anti-horseradish peroxidase (anti-HRPO) (1:2 dilution; $30 \mathrm{~min}$ ), and HPRO ( $2 \mathrm{mg}$ in $20 \mathrm{ml}$ of phosphate-buffered saline (PBS); $30 \mathrm{~min}$ ). Each section was fixed in 2.5\% glutaraldehyde in PBS (30 min), exposed to Hanker-Yates substrate (Polysciences, Warrington, PA; $60 \mathrm{mg} / 40 \mathrm{ml}$ in $0.1 \mathrm{M}$ Tris buffer, $\mathrm{pH} 7.5)$ and $0.4 \mathrm{ml}$ of $1 \%$ hydrogen peroxide ( $8 \mathrm{~min}$ ), post-fixed in $1 \%$ osmium tetroxide $(30 \mathrm{~min})$, dehydrated in a gradient alcohol series, and embedded in Poly/Bed 812 epon (Polysciences, Warrington, PA).Ultrathin sections were counterstained with uranyl acetate and lead citrate and examined under a Zeiss EM10 electron microscope.

\section{RESULTS}

Skin biopsy specimens obtained within the first $10 \mathrm{~d}$ to 3 months of life from each of the four probands were shown to contain intense intracytoplasmic granular deposits of type VII collagen within basilar and, to a lesser extent, suprabasilar keratinocytes, as defined by indirect immunofluorescence with the LH 7:2 monoclonal antibody (Fig $1 A$ ). As previously reported, little or no dermoepidermal junction staining was noted at that time. Identical intracytoplasmic deposits were observed with the L3d monoclonal antibody in each of these four specimens (Fig $1 B$ ), as well as in the skin biopsies from two other affected patients with this disorder who were previously reported by our laboratory, in whom additional biopsies of proband and/or other affected family members were unavailable. Followup biopsies from each proband (patients 1-1, 2-1, and 4-1) in three of the four kindreds demonstrated uniformly linear staining of both (i.e., LH 7:2 and L3d) type VII collagen epitopes along the dermoepidermal junction (Fig $1 C$ ), with staining intensity indistinguishable from that observed in normal control skin. Intraepidermal deposits could no longer be detected despite examination of multi-

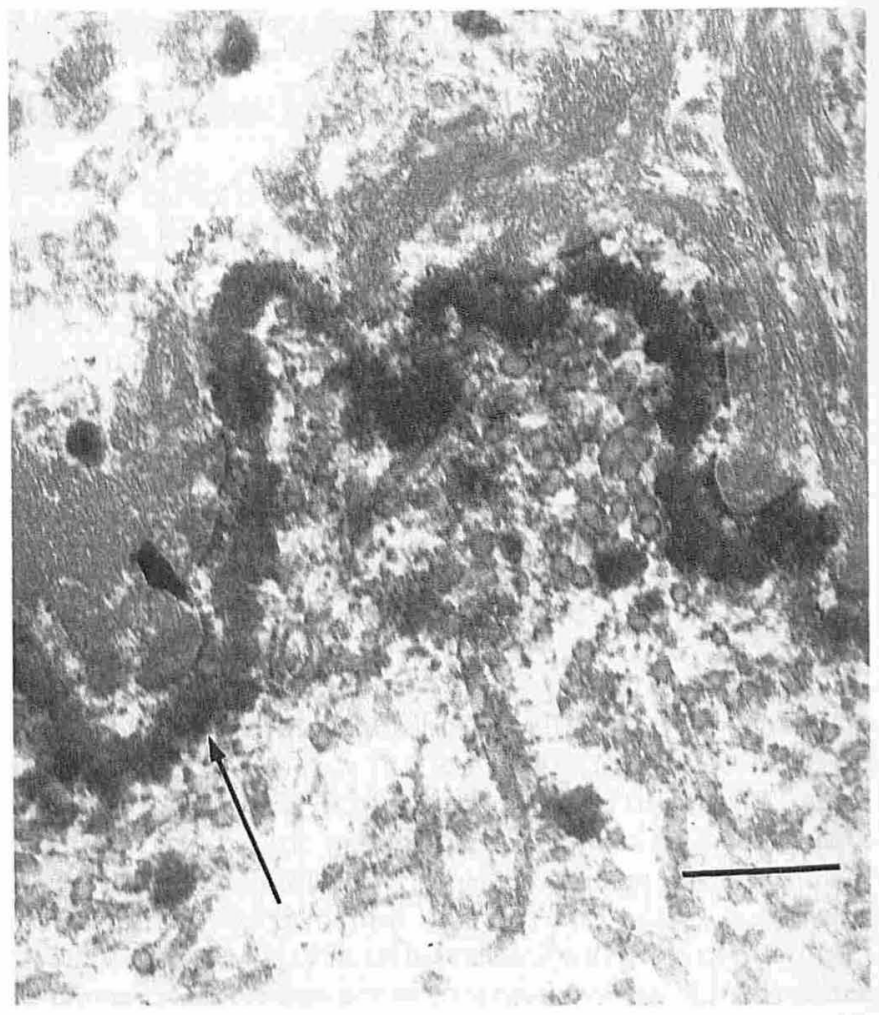

Figure 2. Immunoelectron microscopic study of one of our patients who was biopsied after cessation of all clinical disease activity. Anti-type VII collagen staining is no longer present within the epidermis; rather, immune deposits (arrow) are present solely along the dermoepidermal junction in linear array, identical to that observed in normal human skin (not shown). Bar, $1 \mu$.

ple sections obtained from different depths within each embedded tissue sample. Biopsies from two of these patients were obtained 12 and 36 months after all blisters had ceased to occur, whereas sampling was performed in a third proband (patient 4-1) at age 13 months, during which time diminished numbers of blisters were still developing. Specimens from previously affected relatives of each of these children similarly revealed normal intensity of normal type VII collagen staining (LH 7:2 and L3d epitopes) exclusively along the dermoepidermal junction, identical to findings previously noted in other patients with more classical forms of dominant dystrophic EB.

IIEM was performed on followup biopsy specimens from seven patients. Findings were identical in every specimen studied with each of the two anti-type VII collagen monoclonal antibodies. When the two primary antibodies were employed in more diluted form, linear, interrupted deposits of type VII collagen were noted within the lower lamina densa and/or subjacent upper papillary dermis, a pattern closely approximating the distribution of anchoring fibrils in normal tissue. With increasing primary antibody concentrations, immune deposits became more homogeneous in their linear distribution along the lamina densa (Fig 2). No intracytoplasmic deposits were detectable in any of the specimens. This can be contrasted with the IIEM findings observed during periods of active blistering, when essentially all anti-type VII collagen immunoreactivity was noted intracytoplasmically within clumps or globular collections situated within basilar keratinocytes (Fig 3).

\section{DISCUSSION}

We have previously demonstrated that the intracytoplasmic "stellate bodies" described by Hashimoto et al in a self-limited, rare variant of dystrophic EB referred to as "transient bullous dermolysis of the newborn" represent intracytoplasmic deposits of type VII collagen, and that the usual mode of transmission of this mild dis- 


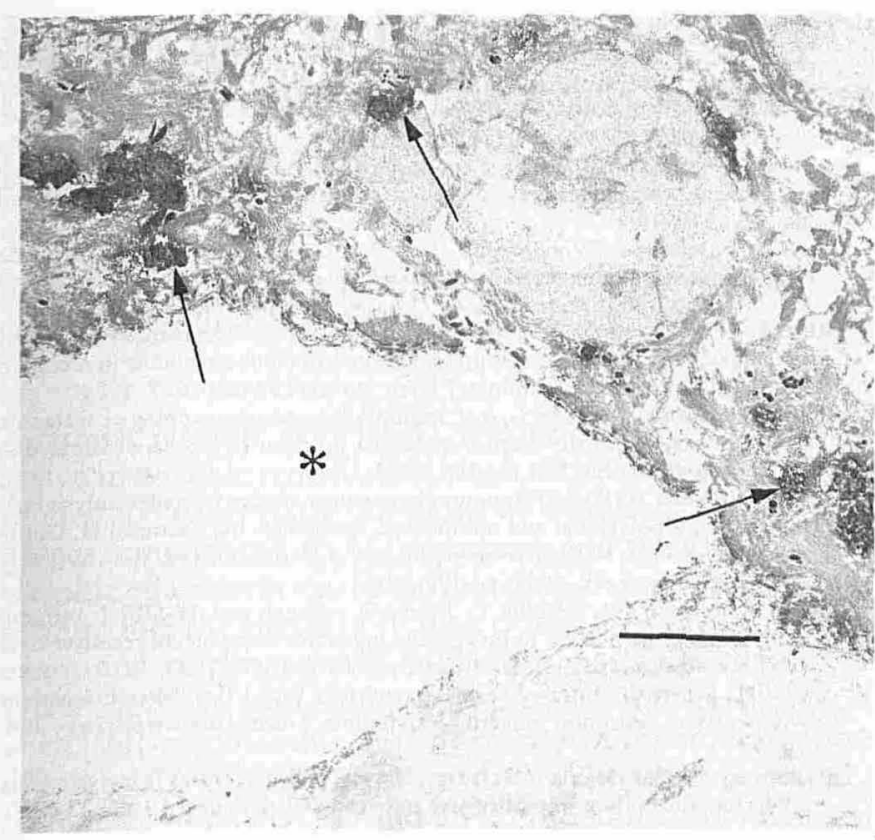

Figure 3. Immunoelectron microscopic study of a case of transient bullous dermolysis of the newborn that was biopsied during early infancy, and while active blistering still occurred. In this particular specimen, anti-type VII collagen staining is exclusively noted in dense collections (arrows) within the cytoplasm of basilar keratinocytes. Only sparse amounts of type VII collagen are detectable within the lamina densa that rims the roof of the blister. Asterisk, blister cavity. Bar, $2 \mu$.

order is autosomal dominant [3]. In the present study, we now report on longitudinal data on two of our four original patients and on identical findings in two additional kindreds. Based on these collective data, it is now possible to better clarify several aspects related to this rare inherited disorder.

As is evident from the pedigrees described in two newly identified families (3 and 4 ), the presence of intraepidermal type VII collagen associated with mild disease activity is transmitted as an autosomal dominant disease. This may be contrasted to a recently published report of a single, rapidly lethal case, also exhibiting intracytoplasmic type VII collagen within the epidermis, which was transmitted in autosomal recessive manner [13]. As predicted by Hashimoto and co-workers $[1,2]$ and suggested by our own previously published data on several identically affected relatives, it is clear that, in general, blisters do cease to occur within the first year of life in the majority of the patients who share these unique immunohistochemi$\mathrm{cal}$ and ultrastructural features. Over two additional years of followup in two of our older patients confirmed the usually self-limited nature of this disorder. With increasing age the skin no longer appears to be mechanically fragile, based on the elicitable history of a lack of trauma-associated blister formation in these children after infancy, as well as our inability to physically induce blistering by the application of rotary traction. However, as illustrated by the clinical features and course observed in family 4 , not all patients with identical intracytoplasmic deposits of type VII collagen experience complete and permanent remission. Whereas the proband (patient 4-1), now 23 months old, develops only a fraction of the number of blisters present during early infancy, he still develops mechanically induced blisters. His father (patient 4-2), never known to have experienced frank blisters, has since childhood developed spontaneous milia over the dorsal fingers, and has several dystrophic toenails and focal atrophic scars. The proband's 11-year-old aunt (patient 4-3), who experienced greater numbers of blisters in infancy, still develops occasional blisters following mechanical trauma, as does the proband's 37-year-old grandmother (patient 4-4). These findings in family 4 are consistent with that expected in a very attenuated variant of dominant dystrophic EB, which is often associated with lessened disease activity with increasing age. Interestingly, one of these latter family members (4-4) even had a sparse number of "albopapuloid"-like lesions, reminiscent of those reported in one of the two major dominant dystrophic EB phenotypes. The documented course in this latter kindred, even if an infrequent presentation for this rare disorder, gives compelling arguments why i) patients with this disease, even when apparently self-limited, do represent the mildest pole in the spectrum of dominant dystrophic $\mathrm{EB}$, and ii) the name "transient bullous dermolysis of the newborn" may be a prognostic misnomer because it may be grossly misinformative as to the true course of disease activity in some individuals. Specifically, kindred 4 illustrates that the disease may continue to be expressed, even if in a rather mild manner, through at least midadulthood and possibly even throughout life. Therefore, this disease entity may be far from "transient" or confined only to the newborn period, despite the presence of identical immunohistochemical findings in patients with widely divergent courses of disease activity.

More intriguing is the realization that the rather dramatic intracytoplasmic array of type VII collagen observed in early infancy is indeed a self-limited event, with a reversal to a normal distribution of this basement membrane component within at least the first few years of life in all patients so far identified. This observation has now been confirmed in an English case, biopsied at age 6 months, which was published after original presentation of the present work [14]. In the latter report, it was also suggested that sparse collections of type VII collagen were present in the skin of two affected siblings, one of whom was biopsied in utero, who represented a clinically mild form of possibly autosomal recessive dystrophic EB, although incomplete penetrance for an autosomal dominant trait could not be excluded.

It is appealing to attribute the rather transient mechanical instability and blistering observed in affected patients in each of our first three kindreds to the temporary entrapment, sequestration, or engulfment of type VII collagen within the lower epidermis. However, it is clear from the experience in kindred 4 that a reduced level of disease activity can still occur long after the abnormal distribution of type VII collagen is reversed. In fact, the findings in the second biopsy from the proband in this latter kindred closely mimic that observed in all other forms of dominant dystrophic EB, that is, apparent normal intensity of dermoepidermal junction staining by anti-type VII collagen antibodies $[4,6,12]$. As such, although a temporal delay or block in the transport of VII collagen from the keratinocyte to the lowermost portion of the basement membrane zone, where it would otherwise be normally assembled into anchoring fibrils, may indeed contribute in early infancy to the tendency for blister formation in those patients with clinically more self-limited disease, other factors not yet identifiable with the current array of anti-type VII collagen antibodies may contribute to the mechanical instability noted at the level of the sub-lamina densa in these patients. Other potential factors may include the presence of point mutations within other domains of the type VII collagen molecule, which would thereby interfere with proper assembly or functioning of anchoring fibrils, the presence of slightly diminished amounts of structurally normal type VII collagen along the dermoepidermal junction, or excessive degradation of this molecule within the uppermost papillary dermis. Any of these possible mechanisms might help to explain, in the absence of any visualizable persistent defect in type VII collagen transport from the keratinocyte to the extracellular matrix, the residual mechanical instability of the basement membrane zone noted in rarer patients. In support of this, recently published work confirms the likelihood of a mutation in one or more portions of the type VII collagen gene in other forms of dominant dystrophic EB [15]. It is clear, however, from studies of normal fetal skin specimens that intracytoplasmic deposits of type VII collagen are not a feature of any developmental step in the ontogeny of this tissue, because this protein is present in linear array along the dermoepidermal junction at the time of its first detection [16]. As such the findings of transient deposits of intracytoplasmic type VII collagen in these unique patients with an attenuated form of dominant dystrophic EB cannot be merely attributed to a physiologic delay in the normal maturation of human skin. Finally, al- 
though we suspect that the findings in these affected patients represent a transient abnormality in transport or secretion of type VII collagen, we cannot exclude the possibility that they may instead represent abnormal phagocytosis of extracellular deposits of type VII collagen by basilar keratinocytes.

We gratefully acknowledge the technical assistance of Mr. Anthony Daniels during the course of this study, Dr. Yuji Horiguchi for his expert assistance with Fig 3, and Drs. Lawrence Schachner, Patricia Ceballos, John Burk, and David Stein for providing us with the original specimens on three of the probands described in this study.

Supported in part by NIH/NIAMS contracts NO1 AR62271, AR22201, and AR22200 (JDF) ad grant AR34861 (JDF), and an NIH grant (RR 000046) to the General Clinical Research Center of the University of North Carolina at Chapel Hill.

\section{REFERENCES}

1. Hashimoto K, Matsumoto M, Iacobelli D: Transient bullous dermolysis of the newborn. Arch Dermatol 121:1429-1438, 1985

2. Hashimoto K, Burk JD, Bale GF, et al: Transient bullous dermolysis of the newborn: two additional cases. J Am Acad Dermatol 21:708 -713, 1989

3. Fine JD, Horiguchi Y, Stein DH, Esterly NB, Leigh IM: Intraepidermal type VII collagen. Evidence for abnormal intracytoplasmic processing of a major basement membrane protein in rare patients with dominant and possibly localized recessive forms of dystrophic epidermolysis bullosa. J Am Acad Dermatol 22:188-195, 1990

4. Heagerty AHM, Kennedy AR, Leigh IM, Purkis P, Eady RAJ: Identification of an epidermal basement membrane defect in recessive forms of dystrophic epidermolysis bullosa by LH 7:2 monoclonal antibody: use in diagnosis. Br J Dermatol 115:125-131, 1986

5. Leigh IM, Purkis P, Bruckner-Tuderman L: LH 7:2 monoclonal antibody detects type VII collagen in the basement membrane of ectodermally derived epithelia including skin. Epithelia 1:17-29, 1987
6. Leigh IM, Eady RAJ, Heagerty AHM, Purkis P, Whitehead PA, Burgeson RA: Type VII collagen is a normal component of epidermal basement membrane which shows altered expression in recessive dystrophic epidermolysis bullosa.J Invest Dermatol 90:639-642, 1988

7. Paller AS, Queen LL, Woodley DT, Gammon WR, O'Keefe EJ, Briggaman RA: A mouse monoclonal antibody against a newly discovered basement membrane component, the epidermolysis bullosa acquisita antigen. $J$ Invest Dermatol $84: 215-217,1985$

8. Paller AS, Queen LL, Woodley DT, Lane AT, Gammon WR, Briggaman RA: Organ-specific, phylogenetic, and ontogenetic distribution of the epidermoly. sis bullosa acquisita antigen. J Invest Dermatol 87:376-379, 1986

9. Rusenko KW, Gammon WR, Fine JD, Briggaman RA: The carboxyl-terminal domain of type VII collagen is present at the basement membrane in recessive dystrophic epidermolysis bullosa. J Invest Dermatol 92:623 -627, 1989

10. Hintner H, Stingl G, Schuler G, et al: Immunofluorescence mapping of antigenic determinants within the dermal-epidermal junction in mechanobullous diseases. I Invest Dermatol 76:113-118, 1981

11. Fine JD, Hintner H, Katz SI: Immunofluorescence studies in epidermolysis bullosa utilizing polyclonal and monoclonal antibodies. In: Beutner EH, Chorzelski TP, Kuman V (eds.). Immunopathology of the Skin, 3rd ed. John Wiley \& Sons, Inc., New York, 1987, pp 399-405

12. Fine JD, Johnson LB, Wright T: Type VII collagen and 19-DEJ-1 antigen: comparison of expression in inversa and generalized variants of recessive dystrophic epidermolysis bullosa. Arch Dermatol 126:1587-1593, 1990

13. Smith LT, Sybert VP: Intra-epidermal retention of type VII collagen in a patien with recessive dystrophic epidermolysis bullosa. J Invest Dermatol 94:261 - 264, 1990

14. Phillips RJ, Harper JI, Lake BD: Intraepidermal collagen type VII in dystrophic epidermolysis bullosa: report of five new cases. Br J Dermatol 126:222-230, 1992

15. Ryynanen M, Knowlton RG, Parente MG, Chung LC, Chu M-l: Human type VI! collagen: genetic linkage of the gene (COL7A1) on chromosome 3 to dominant dystrophic epidermolysis bullosa. Am J Hum Genet 49:797-803, 1991

16. Smith LT, Sakai LY, Burgeson RE, Holbrook KA: Ontogeny of structural components at the dermal-epidermal junction in human embryonic and fetal skin: the appearance of anchoring fibrils and type VII collagen. I Invest Dermatol $90: 480-485,1988$ 